\title{
ОСНОВАНИЯ, ПРЕПЯТСТВУЮЩИЕ РЕГИСТРАЦИИ ГЕОГРАФИЧЕСКОГО УКАЗАНИЯ И НАИМЕНОВАНИЯ МЕСТА ПРОИСХОЖДЕНИЯ ТОВАРОВ
}

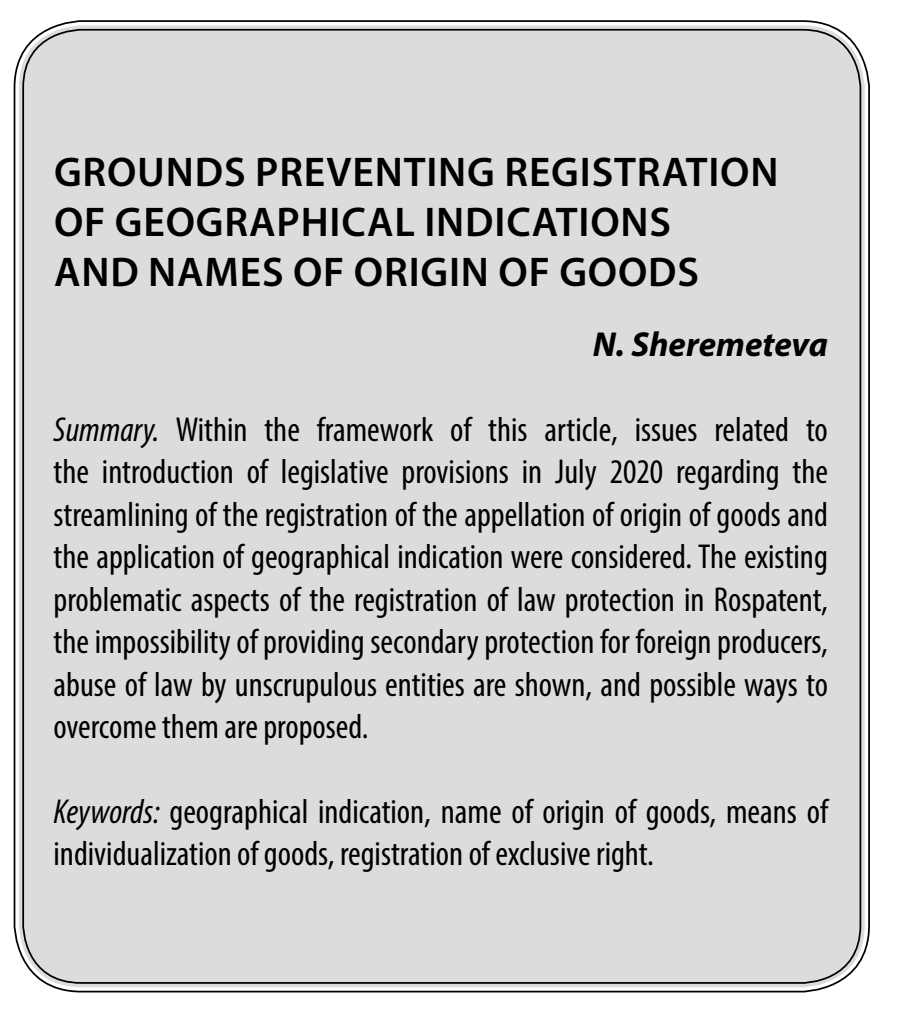

3 ащита региональных товаров и мест их происхождения является на сегодняшний день достаточно острой проблемой в Российской Федерации.

Так, в 2010 году, брянская компания «Умалат» вместе с другими участниками рынка пыталась добиться права производить адыгейский сыр и получили отказ от Роспатента. История судебных тяжб продолжается и по сей день, однако в 2018 году арбитражный апелляционный суд постановил, что продукция «Умалата» не нарушает исключительные права производителей из Адыгеи, поскольку требованиям наименования места происхождения товаров (далее по тексту статьи - НМПТ) не соответствует ни один вид адыгейского сыра. Как указал суд, сыр не формируется в плетеных ивовых корзинах с использованием ручного труда и не имеет ничего общего с современными технологиями - такой способ нарушал бы требования к качеству и безопасности сырья. Также в суде посчитали, что название «Сыр адыгейский» уже давно вошло во всеобщее употребление как обозначение товара, не связанное с местом его производства, поэтому производить его можно в любом регионе без какого-либо ущерба для ре-
Шереметьева Наталья Владимировна

Помощник судьи, Арбитражный суд Приморского края; аспирант, Всероссийский университет юстиции (РПА Минюста России); старший преподаватель, ФГБОУ ВО «Владивостокский государственный университет экономики и сервиса» nata-sheremet@mail.ru

Аннотация. В рамках данной статьи рассмотрены вопросы, связанные С введением в июле 2020 года законодательных положений в части упорядочения регистрации наименования места происхождения товаров и применения географического указания. Показаны существующие проблемные аспекты регистрации охраны права в Роспатенте, невозможности предоставления вторичной охраны для иностранных производителей, злоупотребления правом недобросовестными субъектами, и предложены возможные пути их преодоления.

Ключевые слова: географическое указание, наименование происхождения товара, средства индивидуализации товара, регистрация исключительного права.

гионального бренда. Таким образом, суд постановил, что НМПТ используется не как гарантия качества продукции, а как инструмент конкурентной борьбы [8].

Региональные производители зачастую не имеют представления о порядке регистрации, а если располагают соответствующими познаниями и мотивацией, то времени заниматься вопросами охраны исключительных прав как правило нет. Сложность вопроса заключается в заформализованности процесса регистрации. Для облегчения понимания процедуры предоставления исключительного права Федеральной службой по интеллектуальной собственности разрабатывалась инструкция по порядку регистрации НМПТ. Согласно ее содержанию, Роспатент рекомендует получить заключение уполномоченного органа, предусмотренное п. 5 ст. 1522 ГК РФ [1], то есть получить официальное заключение от регулирующего ведомства или министерства, подтверждающее, что продукт соответствует всем необходимым свойствам. К указанным ведомствам относятся Минздравсоцразвития России, Минпромторг России, Минсельхоз России, Росалкогольрегулирование. 


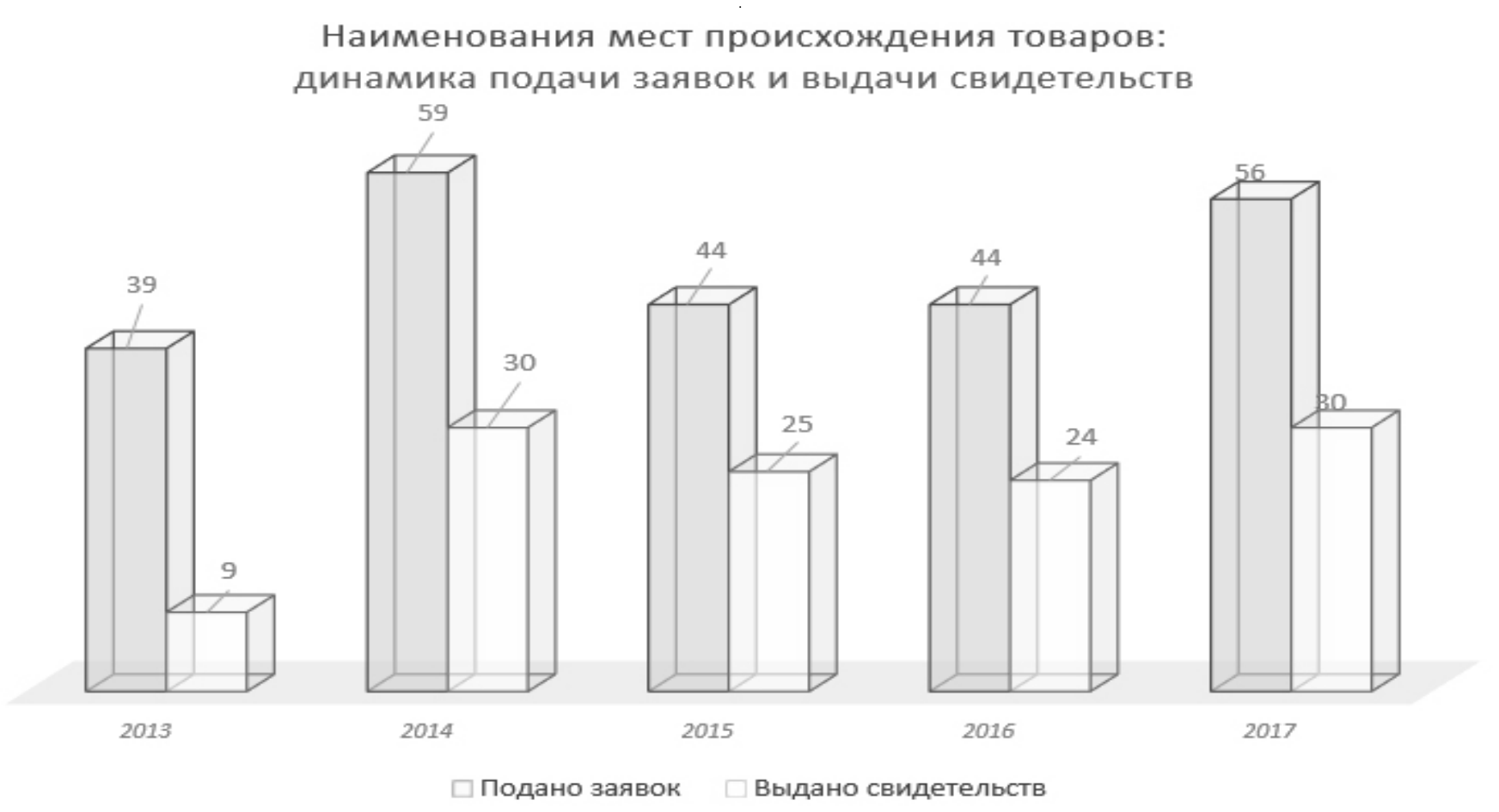

Рис. 1

Сама подача документов в Роспатент не представляет сложностей, главные трудности возникают как раз-таки при получении разрешения от министерств и ведомств. Чтобы получить заключение, необходимо предоставить ведомству пакет документов - в том числе, подтвержденные данные об особенностях происхождения сырья из географического местоположения, об особенностях товара, о зависимости этих свойств от географического местоположения, об условиях и особенностях изготовления товара и так далее. Кроме того, некоторые ведомства могут запросить сведения об участиях товара в выставках и протоколы физико-химических исследований продукции, например - бальнеологическое заключение о лечебных свойствах воды.

Динамика подачи заявок на регистрацию НМПТ находится на низком уровне (рис. 1) ${ }^{1}$. С 1992 года и всего их насчитывается в Роспатенте менее 200.

По данным Роспатента (Федеральной службы по интеллектуальной собственности) на 2018 год, 27 регионов не обращались с заявками вообще. Между тем, законодатель отмечает, что в России имеется потребность в охране большего количества существующих товаров и продукции [3].

${ }^{1}$ Информация с официального сайта Роспатента. - Режим доступа: https://rupto.ru/ru/news/milknews-prostymi-slovami-nmpt-i-geograficheskieukazaniya
Вышеуказанные обстоятельства послужили основанием для рассмотрения на законодательном уровне упрощения порядка регистрации права. Фактически в интеллектуальном праве России с 27 июля 2020 года (в соответствии с введением в действие Федерального закона от 26 июля 2019 г. № 230-Ф3 [2]) будут наличествовать, казалось бы, два дублирующих друг друга средства индивидуализации товара. Но, это только на первый взгляд, и то при недобросовестности использования новых законодательных инструментов. Чтобы избежать указанных обстоятельств законодатель подробно излагает терминологическую разницу между географическим указанием (далее по тексту - ГУ) и НМПТ.

Так, будущая редакция ст. 1516 ГК РФ проводит «водораздел» между ГУ и НМПТ по следующим правовым «маркерам», к сожалению, не введенным в гражданско-правовой оборот, но оказывающих влияние на формирование и формулирование оснований регистрации правовой охраны ГУ и НМПТ. Это:

1. Границы производства товара: для ГУ - это обозначение территории происхождения; качество, репутация, обусловленные географическим местонахождением. Для НМПТ - это обозначение обусловленное уникальным наименованием места или объекта производства товара. Уникальность определяется историческим, культурным, природным, человеческим фактором в привязке к географическому объекту. Таким образом, для 
ГУ важным признаком в характеристике товара является его принадлежность к системе географических координат местности, тогда как для НМПТ ключевым моментом является уникальность и неповторимость места производства товара. Однако для ГУ и НМПТ законодатель использует один и тот же термин «географический объект». Согласно Федеральному закону «О наименованиях географических объектов» [4] к ним относится любое целостное образование планеты Земли (от материка до железнодорожной станции, аэропорта, морского или речного порта). Столь обширная трактовка с позиции гражданско-правовых отношений требует законодательного уточнения.

2. Стадии производства товара: для Гу - хотя бы одна стадия производства товара должна совпадать с границами географического объекта, при чем эта стадия должна быть значимой для всего процесса производства; для НМПТ - весь процесс производства сосредоточен в пределах географического объекта. С точки зрения экономических законов организации технологических процессов производства товаров выделяют как минимум 5 таких этапов [7, С. 8]: 1) подготовительная стадия по проведению первичной подготовки продовольственного и иного сырья; 2) выработка изделия; 3) механическая обработка и сборка; 4) отделка и придание товарного вида; 5) маркирование и упаковка товара.

В целях правильного понимания о каком именно этапе в рамках ч. 1 ст. 1516 ГК РФ идет речь с позиции предоставления правовой охраны ГУ, видится значимым конкретизация стадии производства товара, оказывающей существенное влияние на формирование его характеристик.

Часть 2 ст. 1516 ГК РФ новой редакции устанавливает основания отказа субъекту в регистрации ГУ и МНТП обозначения в шести случаях. Все основания для отказа в регистрации условно можно сгруппировать на относимые к названию (формулировки обозначения), повторности (на условиях соблюдения сохранения обозначения более раннего приоритета), информационной деформации (введение в заблуждение относительно свойств и качеств товара), а также к границам и стадиям производства товара.

Все перечисленные основания размытые и нечеткие, что, на наш взгляд, не будет способствовать продвижению правовой охраны продукции и товаров, произведенных в России. Указанные проблемы требуют устранения уже сейчас, до введения в действие новой редакции параграфа 3 ГК РФ.
Хотелось бы остановится на еще некоторых значимых аспектах, влияющих на надлежащую охрану НМПТ и ГУ. К ним относятся, к примеру, основания получения права охраны для российского и иностранного производителей и их прекращения. Законодатель в настоящий момент в недостаточной степени уделяет внимание вопросу повторности регистрации иностранных обозначений. Выходом из данной ситуации видится внесение соответствующих уточнений в гражданское законодательство о невозможности предоставления вторичной охраны в случае нарушений только правил предоставления правовой охраны для географических указаний. В части прекращения прав охраны географических указаний и НМПТ для иностранных субъектов требуется уже сейчас пересмотреть не введенные в действие новые положения ГК РФ: правовая охрана незамедлительно прекращается на территории РФ в случае прекращения ее в стране происхождения товара. Заслуживают внимания также ряд других вопросов, влияющих на упорядочение регистрации и применения географического указания и НМПТ. К ним относится: закрытость сведений о свойствах товаров, заимствование наименований; возможное злоупотребление правом недобросовестными производителями [5, С. 85]; процедура создания и деятельность объединения производителей и их контрольные функции в отношении удовлетворения продукта требованиям потребителя [6, С. 416-425].

Для решения обозначенных проблем необходимо принятие первоочередных мероприятий, направленных на:

- детализацию и правовую регламентацию границ территорий географических объектов гражданско-правового значения;

- определение стадий производства товаров, подлежащих гражданско-правовой охране, в том числе в конкретном географическом объекте с указанием наиболее значимых для регистрации Гу;

- уточнение оснований отказа в регистрации правовой охраны ГУ и НМПТ с учетом высказанных предположений о возможных злоупотреблениях со стороны недобросовестных производителей и как факторов, провоцирующих коррупционные проявления в министерствах и ведомствах;

- размещение информации о свойствах, общем (неуникальном) содержании товаров, зарегистрированных ГУ и НМПТ в открытых доступом источниках, актуализация которых должна происходить в режиме online;

- повышение результативности государственного и общественного контроля;

- учет и внедрение в правоприменительную деятельность положительного опыта зарубежных стран. 


\section{ЛИТЕРАТУРА}

1. Гражданский кодекс Российской Федерации (часть четвертая) от 18 декабря 2006 г. № 230-Ф3 (ред. от 18.07.2019 г.) // Собрание законодательства РФ.2006. — № 52 (1 ч.).—Ст. 5496.

2. 0 внесении изменений в часть четвертую Гражданского кодекса Российской Федерации и статьи 1 и 23.1 Федерального закона 0 государственном регулировании производства и оборота этилового спирта, алкогольной и спиртосодержащей продукции и об ограничении потребления (распития) алкогольной продукции: федеральный закон от 26 июля 2019 г. № 230-Ф3 // Собрание законодательства РФ.— 2019.— № 30.— Ст. 4132.

3. 0 внесении изменений в часть четвертую Гражданского кодекса Российской Федерации: пояснительная записка к проекту Федерального закона от 13.07.2018 г. № 509994-7 // Система обеспечения законодательной деятельности Государственной Думы РФ.— Режим доступа: https://sozd.duma.gov. ru/bill/509994-7

4. 0 наименованиях географических объектов: федеральный закон от 18 декабря 1997 г. № 152-Ф3 (ред. от 30.12 .2015 г.) // Собрание законодательства.— 1997.— № 51.—С. 5718.

5. Иванов, Н. В. Правовая охрана географического указания и наименования места происхождения товаров / Н. В. Иванов // Наука и образование: хозяйство и экономика; предпринимательство; право и управление.- 2019. — № 8 (111). - C. 81-85.

6. Левдикова, Л. Н. Наименование места происхождения товара как средство индивидуализации / Л. Н. Левдикова // Синергия наук. 一 2020.— № 47.— C. 416-425.

7. Технологические основы производства потребительских товаров: учебное пособие / В.Ф. Финаевнова, Л. Г. Тимуш и др. — Саратов: Сратовкий социально-экономический институт (филиал) РЭУ им. Г. В. Плеханова, 2018. - 112 с.

8. Решение Арбитражного суда Брянской области от 26 ноября 2018 г. по делу № A09-7278/2018 и постановление // Судебные и нормативные акты РФ.Режим доступа: https://sudact.ru/arbitral/doc.

\footnotetext{
( ) Шереметьева Наталья Владимировна ( nata-sheremet@mail.ru ).
}

Журнал «Современная наука: актуальные проблемы теории и практики»

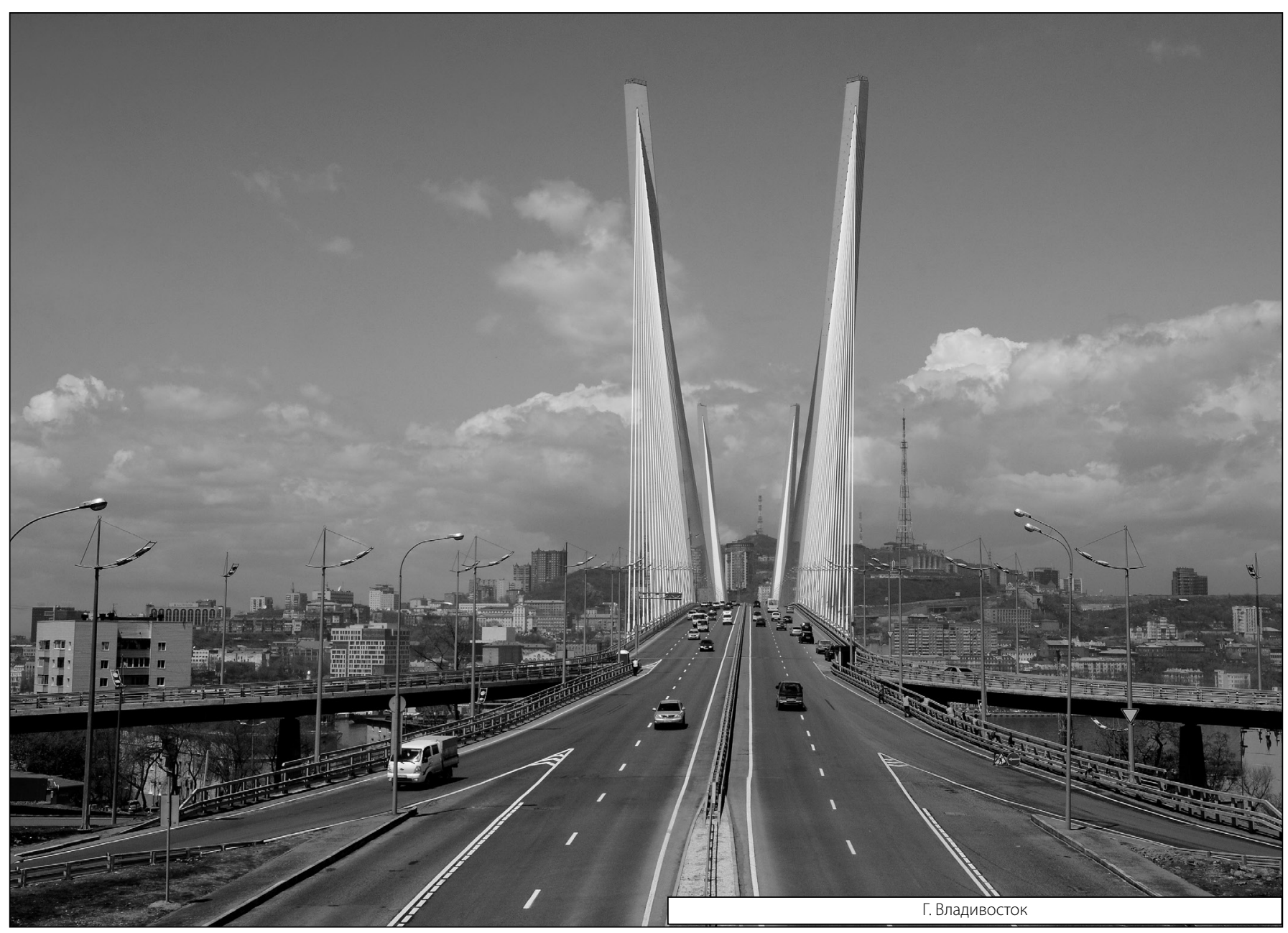

